\title{
Asamblea Local de Cruz Roja Española de Elche (1909-1930)
}

\author{
Local Assembly of the Spanish Red Cross of Elche (1909-1930) \\ Assembléia local da Cruz Vermelha Espanhola de Elche (1909-1930)
}

\section{María Rosa Gómez Martínez}

Doctora en Sociología por Universidad de Alicante

Cómo citar este artículo en edición digital: Gómez Martínez, M. ${ }^{a}$ R. (2020). Asamblea Local de Cruz Roja Española de Elche (1909-1930). Cultura de los Cuidados (Edición digital), 24 (57) Recuperado de http://dx.doi.org/10.14198/cuid.2020.57.09

Correspondencia: Remitirse al correo electrónjico.

Correo electrónico: mariarosa.gomez@um.es

Recibido:18/11/2019

Aceptado:23/03/2020

\begin{abstract}
The Local Assembly of the Spanish Red Cross of Elche began its formal activity in September 1909; the altruistic mood of the "brigade of stretchers" and its economic life, mainly composed of membership fees, grants from the city council and fundraising celebrations, as well as services provided for
\end{abstract}

the entire population, warn of the existence of health coverage in a moment of singular value, as is the dictatorship of Miguel Primo de Rivera. The principles governing the Assembly are the same as those proposed by the International Committee of the Red Cross in 1921: charity, universality, independence and impartiality. Objective: 
identify what is known about the beginnings of the Spanish Red Cross in the city of Elche and the relationship with its principles: charity, universality, independence and impartiality. Method: a historical investigation based on the literature review was carried out. Documentary sources: documentary catalogs of libraries and documentary archives, electronic databases, catalogs of magazines specialized in history and other network sources. Descriptors used: Red Cross, Spanish Red Cross, Local Red Cross. Results: the analysis included documents from studies based on primary sources and the results are presented in 4 sections: Composition and economic life, Celebrations to raise funds: the Feast of the Banderita, Municipal Agreements and Services provided. Conclusion: there is a clear relationship of the work carried out by the Assembly of the Spanish Red Cross of Elche and the principles on which it is oriented, developing each of them in their daily lives; This follows from the documents analyzed at the time of both the communications and the minutes of the town hall and the historical press.

KeyWord: Charity, History of the Red Cross, Relief House, Urban Health Ambulance, Camilleros, Red Cross Ladies.

\section{RESUMEN}

La Asamblea Local de Cruz Roja Española de Elche inició su andadura con carácter formal en el mes de septiembre de 1909; el talante altruista de la "brigada de camilleros” y su vida económica, compuesta principalmente por cuotas de socios, subvenciones del ayuntamiento y celebraciones para recaudar fondos, así como los servicios prestados para toda la población, advierten de la existencia de cobertura sanitaria en un momento de valor singular, como es la dictadura de Miguel Primo de Rivera. Los principios que rigen la Asamblea son los mismos que propone el Comité Internacional de la Cruz Roja en 1921: caridad, universalidad, independencia e imparcialidad. Objetivo: identificar qué se conoce sobre los inicios de la Cruz Roja Española en la ciudad de Elche y la relación existente con sus principios: caridad, universalidad, independencia e imparcialidad. Método: se llevó a cabo una investigación histórica basada en la revisión bibliográfica. Fuentes documentales: catálogos documentales de bibliotecas y archivos documentales, bases de datos electrónicas, catálogos de revistas especializadas en historia y otras fuentes de red. Descriptores utilizados: Cruz Roja, Cruz Roja Española, Cruz Roja Local. Resultados: en el análisis se incluyeron documentos procedentes de estudios basados en fuentes primarias y los resultados se presentan en 4 apartados: Composición y vida económica, Celebraciones para recaudar fondos: la Fiesta de la Banderita, Acuerdos municipales y Servicios prestados. Conclusión: existe una clara relación de la labor desarrollada por la Asamblea de la Cruz Roja Española de Elche y los

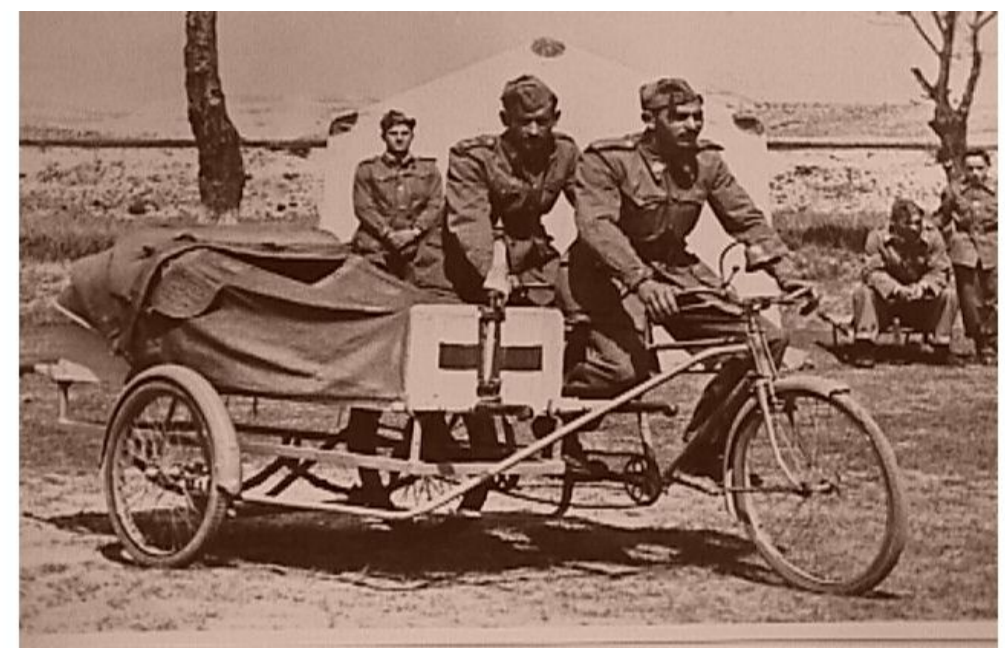


principios en los que se orienta, desarrollando cada uno de ellos en su vida cotidiana; así se deprende de los documentos analizados de la época tanto de comunicaciones y actas del ayuntamiento como de prensa histórica.

Palabras clave: Caridad, Historia de Cruz Roja, Casa de Socorro, Ambulancia Sanitaria Urbana, Camilleros, Damas de Cruz Roja.

\section{RESUMO}

A Assembléia Local da Cruz Vermelha Espanhola de Elche iniciou sua atividade formal em setembro de 1909; o humor altruísta da "brigada de macas” e sua vida econômica, composta principalmente de honorários, subsídios da prefeitura e celebrações de arrecadação de fundos, além de serviços prestados a toda a população, alertam para a existência de cobertura de saúde momento de valor singular, como é a ditadura de Miguel Primo de Rivera. Os princípios que governam a Assembléia são os mesmos propostos pelo Comitê Internacional da Cruz Vermelha em 1921: caridade, universalidade, independência e imparcialidade. Objetivo: identificar o que se sabe sobre o início da Cruz Vermelha Espanhola na cidade de Elche e a relação existente com seus princípios: caridade, universalidade, independência e imparcialidade. Método: foi realizada uma investigação histórica baseada na revisão da literatura. Fontes documentais: catálogos documentais de bibliotecas e arquivos documentais, bancos de dados eletrônicos, catálogos de revistas especializadas em história e outras fontes de rede. Descritores utilizados: Cruz Vermelha, Cruz Vermelha Espanhola, Cruz Vermelha Local. Resultados: documentos de estudos baseados em fontes primárias foram incluídos na análise e os resultados são apresentados em 4 seções: Composição e vida econômica, Celebrações para captação de recursos: Festa da Banderita, Acordos e Serviços Municipais. Conclusão: existe uma clara relação entre o trabalho realizado pela Assembléia da Cruz Vermelha Espanhola de Elche e os princípios sobre os quais se orienta, desenvolvendo cada um deles no seu cotidiano; Isso decorre dos documentos analisados na época das comunicações e das atas da prefeitura e da imprensa histórica.

Palavras-chave: Caridade, História da Cruz Vermelha, Casa de Socorro, Ambulância de Saúde Urbana, Camilleros, Cruz Vermelha Feminina.

\section{INTRODUCCIÓN}

La Real Orden de Isabel II de 6 de julio de 1864 y su posterior publicación de 31 de julio de 1868 establece los estatutos recogidos de la Asamblea de la Asociación Internacional de socorros a heridos en campaña, reconociendo a la Cruz Roja como “sociedad de utilidad pública” (Clemente, 2001). En 1918, por los conflictos bélicos acaecidos en África y la epidemia de gripe, entre otros, se origina un enérgico desarrollo de centros sanitarios y personal a su servicio 
Revista científica de la Asociación de Historia y Antropología de los Cuidados (Universidad de Alicante)

(Hernández-Conesa, 2014). En 1921 el Un segundo objetivo trata de analizar a

Comité Internacional de la Cruz Roja adopta cuatro principios que estuvieron vigentes desde su génesis hasta 1964: caridad, universalidad, independencia e imparcialidad, señas de identidad de la institución en todos los ámbitos y en todos los niveles de actuación (Más Espejo, 2016). En 1965 en la XX Conferencia Internacional de la Cruz Roja de Viena se definen y aprueban los principios fundamentales actualmente en vigor: humanidad, imparcialidad, neutralidad, independencia, carácter voluntario, unidad y universalidad. Será la dictadura de Primo de Rivera un período de importante tarea reformista sanitaria, siendo para la Cruz Roja un momento de prosperidad (Siles, 1996).

Un primer objetivo expone la narrativa social de los documentos localizados en el Archivo Histórico Municipal de Elche (AHME): correspondencia, legajos, prensa histórica local, comunicaciones u otra documentación relacionados con el objeto de estudio, en un intento de hacer una reconstrucción socio-histórica y cultural o historia social (Gómez Martínez, 2018:24) de la vida cotidiana de la Asamblea Local de Cruz Roja de Elche (ALCRE). La importancia de la vida cotidiana en la historiografía contemporánea reside en mostrar la experiencia ordinaria como punto de partida desentrañando su problemática y dando respuesta a los valores dominantes de esa sociedad (Burke, 1996:24). través de la narrativa de la otredad cómo están presentes y activos los principios que vehiculan el quehacer diario de la CruzRoja Internacional.

\section{METODOLOGÍA}

El proceso de investigación del siguiente estudio constó de 3 fases: primero se realizó un examen exhaustivo de la documentación municipal existente en el Archivo Histórico Municipal de Elche (AHME) y de revisión de la prensa histórica existente en la Biblioteca Municipal de Elche; el análisis de las noticias, artículos o publicidad de un período concreto puede indicarnos cuál es el papel de la sociedad respecto al objeto de estudio (Martínez, Juárez, Solano y Siles-González, 2017); posteriormente se procedió a una revisión bibliográfica de las publicaciones existentes respecto a la Cruz Roja desde su dimensión sanitaria, sociohistórica y antropológica; en un tercer momento se realizó una búsqueda en los diferentes recursos electrónicos y bases de datos (CUIDEN, SCIELO y DIALNET) atendiendo a las palabras: Historia de Cruz Roja, Cruz Roja Española, Cruz Roja Local.

\section{COMPOSICIÓN Y VIDA ECONÓMICA}


El 2 de Enero de 1907 se produce en

Alicante una manifestación obrera que acaba con un enfrentamiento con la Guardia Civil con varios muertos y heridos; los agentes de seguridad habían repelido el lanzamiento de piedras con el uso de armas de fuego. La brigada sanitaria de camilleros también recibe descargas por meterse entre el fuego para recoger a los heridos. En Septiembre y Octubre las regiones catalana y andaluza son azotadas por grandes lluvias afectando a un gran número de poblaciones; la Cruz Roja envía recursos para los damnificados (Clemente; Polo, 2003:111-112).

La fundación de la Cruz Roja Española en la ciudad de Elche data del 12 de septiembre de 1909, debiéndose principalmente su verdadera organización a Tomás Sempere Juan, comandante retirado de la Guardia Civil que consigue que un grupo de hombres se agrupen para hacer el bien al prójimo y es su primer presidente (Democracia, 26-09-1909; La Perla, 11-091909); para otros autores será Santiago Pomares Ibarra el responsable de dicha convocatoria teniendo la sede actividad no formal desde finales del siglo XIX (Monge, 2015); en 1910 la primera Sede Social se sitúa en la calle de Nuestra Señora de los Desamparados $\mathrm{n}^{\circ} \quad 2$ ejerciendo de practicantes de la sección primera José Jiménez Coves y José Esteve Penalva (Ors Montenegro, 2010); en 1915 la Sede se traslada a la plaza de María Guerrero.

La "Cruz Roja”: ese es el emblema adoptado por esta asociación internacional... a su sombra parece volver a la vida el moribundo y al flotar sobre las sienes del herido... su oficio es ir a dónde se vierte sangre del hombre para restañarla. No espera más premio que el de su conciencia satisfecha y pone de relieve el heroico desinterés de todos los asociados en aras del pensamiento caritativo que los impulsa (El Tío Paco, 18-09-1909).

A Tomás Sempere le sustituye Antonio Sánchez Bernad, delegadopresidente de la $A L C R E$ en 1926. La Cruz Roja se ubica en la Plaza del Esparto donde tiene montado un dispensario de urgencia, con material quirúrgico y botiquín. Diariamente se practican 5 curaciones, estando al frente el jefe médico de la Brigada y el forense de la ciudad, Carmelo Serrano García. A estos hay que sumar la Brigadade Camilleros, que está compuesta en su totalidad por honrados trabajadores, que, alistados en filas voluntarias de la Caridad, prestan su abogado concurso. En 1927 la Brigada de Camilleros consta de un jefe, tres oficiales, dos sargentos, siete cabos y 35 camilleros; de estos 35 se destina el número suficiente para el servicio de 6 camillas, cada una de las que tiene adscrito un botiquín; los restantes forman la Sección ciclista, Escuadra de gastadores y Banda de cornetas y tambores. A la Brigada va afecto un jefe facultativo (médico), dos practicantes y un capellán. 
Revista científica de la Asociación de Historia y Antropología de los Cuidados (Universidad de Alicante)

Los Camilleros son hombres puestos al servicio de los demás, llevados a ello por el sólo impulso del corazón, movidos por el estímulo altruista del cariño a sus hermanos, que son para todos ellos, absolutamente todos los seres humanos, sin distinción de ninguna especie. Allá donde hay un ser desgraciado que necesita auxilio, allá va un Camillero de la Cruz Roja, ese Ángel en forma humana que ni rehúye trabajo por penoso que sea, ni vuelve la cara ante la desgracia por espantosa que aparezca (Elche, 2412-1927).

Figura 1. Brigada de Camilleros.

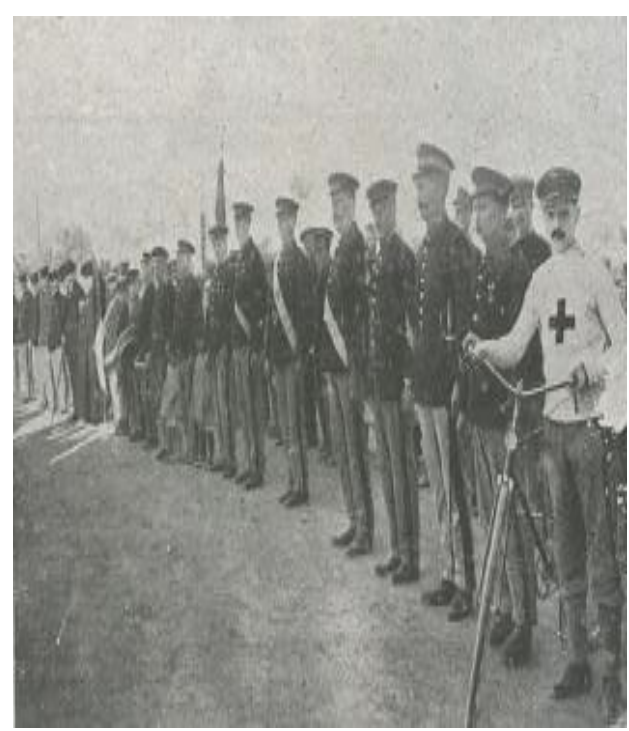

(Fuente: Elche, Año I, n ${ }^{\circ} 24$, Diciembre de 1927).

La vida económica de la entidad se debe a la cooperación de un centenar de socios y a la subvención de 250 pesetas que tiene concedida por el Ayuntamiento de la ciudad (Levante, 20-12-1925). En el Movimiento de caja del Ayuntamiento de la ciudad del mes de Octubre de 1923 se registran 75 pesetas por alquileres de locales de la Cruz Roja; en Febrero y Abril de 1924 sólo aparece alquiler por un importe de 25 pesetas. En el mes de Noviembre se pagan 25 pesetas a camilleros de Cruz Roja por traslado de cadáveres (Nueva Illice, 11-111923 y 16-12-1923; Renovación, 06-031924 y 19-10-1924); el mes de Octubre de 1924 registra un pago de 80 pesetas para alquiler de Cruz Roja y material sanitario (Renovación, 26-02-1925).

El 29 de Junio de 1924 la Comisión de Partido de Elche de Cruz Roja Española comunica a los médicos, practicantes y personal subalterno de la Ambulancia Urbana Local que la institución se traslada de domicilio social a la Plaza del Esparto; allí quedan ubicadas sus oficinas, el parque de Camilleros y el dispensario de urgencia desde el 1 de Julio de 1924; la inauguración oficial se produce el 13 de Julio de 1924; el nuevo edificio es una casa de moderna construcción que reúne todas aquellas condiciones de higiene y comodidad precisas al fin para que se la destina (Nueva Illice, 29-06-1924 y 13-07-1924). En Agosto de 1924 el semanario La Defensa publica una pequeña reseña respecto a la Cruz Roja de la mano de Milagros Gómez Soler, viuda de Navarro, con el título "Pluma de mujer”:

La Cruz Roja, sociedad mundial, es corpulento árbol cuyas frondosas 
ramas sostenidas en España por las regias manos de nuestra augusta soberana (que Dios guarde), dan vida con su savia a la más sublime de las virtudes, la caridad... (24-08-1924).

Nueva Illice felicita a la escritora del artículo y al señor Sánchez Bernad por la labor que desarrollan en beneficio de la humanidad doliente (La Defensa, 24-08-1924; Nueva Illice, 19-10-1924). En Mayo de 1928, Milagros Gómez volverá a ser felicitada como ilustre presidenta de la Cruz Roja y notable escritora, colaboradora del semanario (El Día, 29-05-1928). Milagros Gómez Soler (1859-?) escritora ilicitana, publicó El castigo junto al crimen (Alicante, A. Reus, 1882), Un poema de dolor (Alicante, A. Reus, 1884) y Hojas Secas (Alicante, A. Reus, 1889); colaboró habitualmente en la prensa ilicitana: La idea, El Vinalopó, El Eco Liberal, El Pueblo de Elche, Justicia, Hojas Morales, La Defensa, Nueva Illice, Elche, El Ilicitano, El Popular y La Opinión; probablemente fuela primera mujer en escribir en la prensa ilicitana; contribuyó a difundir la labor de Cruz Roja en la ciudad siendo socia activa.

Figura 2. Junta de Damas de la $A L C R E$

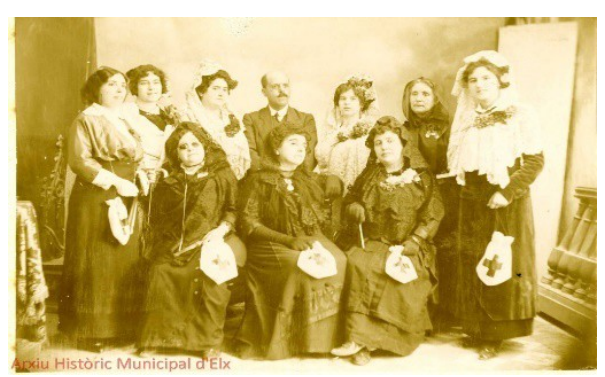

(Fuente: Archivo Histórico Municipal de Elche, 1927, Sig. AF772)
Ya en 1911 la Asamblea Suprema de Cruz Roja otorga a Milagros Gómez la Medalla de Plata por sus meritorios servicios y en 1915 es condecorada de nuevo con la Medalla de Oro (Ors Montenegro, 1984). Seguirá así el impulso de la reina Victoria Eugenia que pretendía contagiar a su entorno más próximo acercándose a asociaciones de mujeres bien acomodadas (Lujano y Ruiz, 2019:5).

En el mes de Octubre de 1924, Sánchez Bernad comunica al alcalde de la ciudad que, según disponen los nuevos estatutos, se ha reorganizado la Comisión de la Cruz Roja fusionándose con la Sección de Señoras, formando una Sección única que se denominará ALCRE; el delegado ofrece sus respetos a la autoridad y pone a su disposición el Instituto en beneficio del bien público (Comunicación d 151, 25-10-1924). “¿Para qué sirve la Cruz Roja?” es el título de una pequeña nota que hace el semanario Juventud sobre la Cruz Roja y la no permanencia de sus empleados:

¿Para dar bombo a una fachada ostentando esa insignia, símbolo de humanitarismo y de civilización? Porque no será por la permanencia continua del personal sanitario empleado en este benéfico establecimiento. Verdaderamente un escándalo. Nosotros, pedimos al Ayuntamiento, ya que depende de él el citado dispensario, que vigile para que cumplan sus empleados; 
Revista científica de la Asociación de Historia y Antropología de los Cuidados (Universidad de Alicante)

La respuesta de Sánchez Bernad al correspondiente recibo talonario (b 342/9, semanario es que el Dispensario es 26-10-1912).

exclusivamente de dicha asociación e

En 1913, Nueva Illice recoge varios independiente de la Corporación Municipal; el personal que presta sus servicios lo hace por altruismo y gratuitamente (Juventud, 3105-1925 y 07-06-1925). Al mes siguiente el delegado responde al semanario de una forma más completa porque piensa que tergiversa la verdad de los hechosocurridos; dice que el dispensario de la Cruz Roja está subvencionado con 80 pesetas mensuales, cantidad que se destina íntegra al pago de los alquileres de la casa social; todos los gastos que origina el establecimiento se sufragan con las cuotas de sus asociados y con lo que se recauda por colectas, beneficios, festivales y donativos particulares; todo el personal que presta sus servicios lo hace por altruismo excepto el conserje, que cobra 1,25 pesetas diarias, siendo el encargado del cobro de las cuotas, limpieza del local y demás obligaciones de su cargo (Nueva Illice, 07-06-1925).

\section{CELEBRACIONES PARA RECAUDAR FONDOS: LA FIESTA DE LA BANDERITA}

En octubre de 1912, la Cruz Roja Española autoriza a todas sus delegaciones y comisiones para que acepten donativos en metálico para la guerra de los Balcanes; la sede de Elche recibe los mismos para tal objeto entregando a los donantes el donativos de ilicitanos para la Cruz Roja: Leandro Román dona un estuche de nogal con varios instrumentos de cirugía y Joaquín Pérez un litro de alcohol para la Casa de Socorro (07-06-1913). "La dama de la Cruz Roja en la guerra” es publicación de actualidad de Antonio Heredero (Trabajo, 02-01-1916). En el mes de Junio de 1924 se prepara un hermoso festival en la Glorieta cuyos productos son destinados al sostenimiento del dispensario y adquisición de material sanitario y de curación para la Ambulancia Sanitaria Urbana de la Cruz Roja. Organiza la fiesta la Junta de Damas que acudirá con la Brigada de Camilleros, banderas y banda de cornetas y tambores; la banda de música Blanco y Negro tomará parte en la fiesta. En esta fiesta de caridad las señoritas de la localidad harán una colecta para el sostenimiento de la Casa de Socorro que tiene establecida la Cruz Roja obsequiando con flores a los donantes cedidas por el alcalde; las heroínas del éxito de la recaudación obtienen la cifra de 1.303,55 pesetas; los ilicitanos prestan su cooperación en función de su estado y posición social (El Papagayo, La Defensa, Nueva Illice y Renovación, 01 y 08-061924). El mismo mes se recibe una comunicación de propaganda de la Lotería Nacional; en ella se van a sortear grandes premios a beneficio de la Cruz Roja y de la Lucha Antituberculosa; el evento será en 
Madrid el día 11 de Octubre de 1924. Se venderán 48.000 billetes a 250 pesetas cada uno divididos en décimos de 25 pesetas (Nueva Illice, 10-08-1924; Comunicación d 150, s/f junio 1924).

A finales del mes de Mayo de 1925 se proyecta la celebración de un festival por la $A L C R E$ para conseguir recursos con destino al sostenimiento de su Casa de Socorro y Ambulancia Sanitaria Urbana; en esta ocasión va a cooperar la Banda Municipal de Música, cedida por el alcalde Gabriel Ruiz Chorro, que, de su cuenta, vaa ofrecer todas las flores que se necesiten para el evento (Nueva Illice, 31-05-1925). El mismo mes juegan un partido benéfico para el Hospital de la Cruz Roja la Real Sociedad de San Sebastián y el Club Natación (Juventud, 04-05-1925).

En el mes de Agosto de 1925 se celebran los Juegos Florales de Albacete, organizados por la Asamblea Local de la Cruz Roja Española; como temas relacionados con la Cruz Roja de corte jurídico, social y sanitario destacan: "Cartilla popular contra los remedios caseros que la Ciencia juzga inútiles o perjudiciales", "La mujer como eficaz colaboradora de los servicios encomendados a la Cruz Roja”, "Influencia del Derecho en las nuevas orientaciones sociales”, "Nociones de Higiene Femenina para uso de las enfermeras de la Cruz Roja”, "Orientaciones para resolver el problema de la vivienda y de la construcción de casas”, "Disposiciones legales que podrían aconsejarse conducentes a la solución de estos problemas” (Nueva Illice, 23-081925).

A finales de año se le encarga a la Cruz Roja Española que colabore con la obra "Aguinaldo del soldado" que tan insustituibles consuelos lleva el ánimo de los bravos defensores de la Patria; la ALCRE recibe donativos para tan altruista fin tanto en efectivo como en especie, en forma de ropas y víveres. También hay un proyecto para la celebración de un acto público conla cooperación de las entidades artísticas de la ciudad para recaudar la mayor suma destinada a tal fin (Amanecer, 06-12-1925; Levante, 05-12-1925).

En Mayo de 1927 se organiza la Fiesta de la Banderita de la Cruz Roja; la Cruz Roja deseosa de colaborar a favor de los damnificados por los últimos temporales en Santa Pola, dispone que el 25\% del total de la recaudación de la Fiesta sirva para engrosar la mencionada suscripción; para motivar a la población se regala un número a todos los que, al entrar en la Glorieta, entreguen un donativo de 10 a 25 céntimos; al final de la Fiesta se hace un sorteo entregando al número premiado la figura artística de un escaparate del comercio de Juan Brufal, en la calle Victoria. Este objeto es de los sobrantes de la Tómbola organizada por las señoras de la Cruz Roja en Agosto de 1921; se conservan en la casa social y, ya que proceden del pueblo, es muy justo que vuelvan otra vez al pueblo. La recaudación obtenida en la Fiesta asciende a 683 pesetas; de ellas se han entregado 215,75 a la alcaldía para la suscripción iniciada por el 
Revista científica de la Asociación de Historia y Antropología de los Cuidados (Universidad de Alicante)

Ayuntamiento con destino a los La situación de la política sanitaria

santapolenses; el resto se ingresa en la Caja de la $A L C R$ de la ciudad (Amanecer, 08-051927; La Defensa, 29-05-1927 y 05-061927).

En el mes de Diciembre de 1928, como todos los años, se celebra la fiesta de la Patrona de la Cruz Roja el día de la Inmaculada Concepción o la Purísima; después del desfile de los Camilleros las señoras reparten limosnas a enfermos pobres visitando los domicilios de los mismos; también se distribuyen en el pórtico de la Casa Consistorial 400 tapabocas para niño y cubrecorsés de punto inglés para niña donados por el alcalde para los niños y niñas pobres de la ciudad (Nueva Illice, 16-121923; La Defensa, 23-12-1928; El Ilicitano, 02-12-1928).

En Julio de 1930 la $A L C R E$ presenta una instancia dirigida al Gobernador Civil de la Provincia solicitando permiso para la instalación de una Tómbola Benéfica a beneficio de la Institución, rogándole que le dé curso con la mayor brevedad posible (Comunicación d 163, 29-07-1930).

\section{ACUERDOS MUNICIPALES}

En Octubre de 1925 Sánchez Bernad quiere hacer constar en acta la gratitud de la Cruz Roja hacia la Corporación municipal; el motivo de tal proceder es el aumento de la subvención para el alquiler y sostenimiento del Dispensario de urgencia (Comunicación d 155/1, 17-10-1925). en la ciudad es analizada por Francisco Quesada en el semanario Trabajo en Marzo de 1924; la realidad es que no existe un Laboratorio donde pobres y ricos puedan servirse de la ciencia investigadora de su microbiología y bacteriología; cómo explicar que una ciudad de 30.000 habitantes carece de casa de Socorro de asistencia inmediata; la mayoría de los obreros, por su precaria situación económica, carecen del dinero para afrontar la asistencia médica... aunque existe la Cruz Roja... pero es de justicia que esta asistencia sea en local ad hoc montado por el Ayuntamiento; en pueblos de igual categoría sí existen (Trabajo, 30-03-1924). En Diciembre de 1925 el semanario Levante entrevista a Antonio Sánchez Bernad de la mano de Lucio Poncio; se trata el tema del Estatuto Municipal que dispone que las poblaciones de más de 20.000 habitantes sean obligadas al sostenimiento de una Casa de Socorro; el Delegado responde que, de ser así,

la ciudad dispone de una Casa de Socorro ya montada y muy bien podría aumentar la consignación a la Cruz Roja la Corporación Municipal, para que esta organizase el servicio permanente, con personal facultativo. Es esta una mejora necesaria en nuestra población, en atención a que dado lo numeroso e importante de su industria, existe el peligro constante 
de desgraciados accidentes que requieren inmediata intervención (Levante, 20-12-1925).

A finales de 1927 el semanario Elche habla del doctor José María López Campello (1861-1933) como uno de los médicos que ejerce su profesión en la benéfica institución de la Cruz Roja; es su valiosísima ayuda de gran importancia, con su especialidad de “Enfermedades del Aparato Digestivo”. Este médico español, nacido en Elche en 1861, es redactor de la Revista Iberoamericana de Ciencias Médicas, y colaborador de otras publicaciones importantes. El Ateneo de Madrid lo ha elegido para formar parte de su junta directiva con el cargo de depositario, donde ejerce su profesión de médico. En este período vive en Alicante, siendo el consuelo de los enfermos y el ángel de la caridad para los pobres que necesitan sus auxilios $y$, a los que atiende, tal vez por su humilde condición, con más solicitud y cariño (Elche, 18-12-1927).

En Enero de 1930 el consistorio acuerda, en sesión extraordinaria, el concurso para proveer en propiedad cuatro vacantes de Practicantes de cirugía menor para guardia permanente en la Casa de Socorro o en el Dispensario de la Cruz Roja, que desempeña el servicio en la actualidad (Acta 227, 13-01-1930:6-12); ya en 1923 el practicante era considerado una persona perita, con un título profesional de esfera limitada que ejecutaba prescripciones del médico (González, 2013:21).
Figura 3. Detalle del ParqueAlmacén de material.

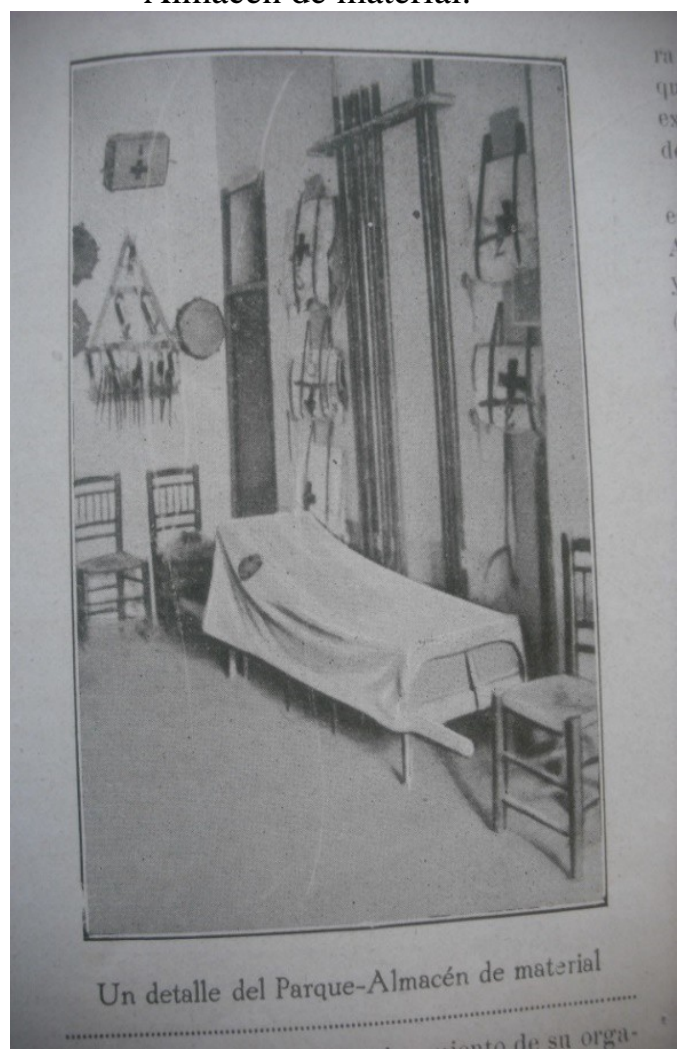

(Fuente: Elche, Año I, n ${ }^{\circ} 24$, Diciembre, 1927).

Para finales de año la subvención a la Cruz Roja por el servicio de la Casa de Socorro es de 3.000 pesetas; el salario mensual de los 4 practicantes de la Casa de Socorro asciende a 750 pesetas cada uno; la gratificación del Director de la Sub-brigada sanitaria para el mes de Marzo de 1928 es de 1.500 pesetas (Comunicación d 159/2, 30-03-1928).

constituye esta una importante mejora en el servicio local de Sanidad... aplaudimos al alcalde, que no olvida el aspecto sanitario de la vida local; al montar este servicio dejará de ocurrir lo que sucedía antes: que el herido, mientras se buscaba a un 
Revista científica de la Asociación de Historia y Antropología de los Cuidados (Universidad de Alicante)

médico o practicante, transcurría media hora, tiempo suficiente para que, en caso grave, pudiera morir por falta de asistencia (Comunicación d 163, 22-02-1930; La Voz de Levante, 15-01-1930 y 19-01-1930).

En el mes de Enero de 1928 la Comisión Permanente de la ciudad cede a la Cruz Roja una parcela de terreno de 45,15 metros cuadrados, libre de gastos e impuestos, en el Cementerio General para enterramientos del personal subalterno que fallezca, afecto a la Ambulancia Sanitaria Urbana (Legajo 1498/9); el Delegado de ALCRE agradece la distinción que ha tenido el Consistorio al atender dicha solicitud (Comunicación d 161, 12-10-1929).

Figura 4. Ciclo-camilla de la Cruz Roja, años 20.

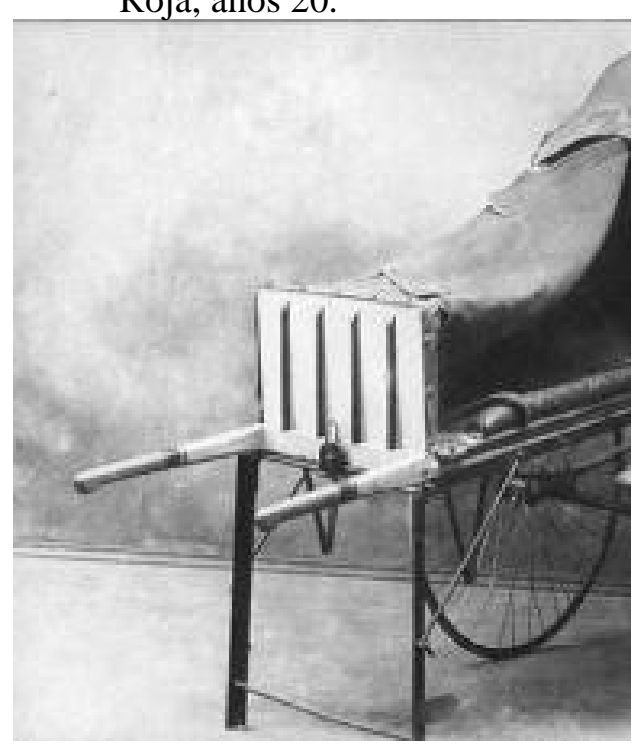

(Fuente: lamiradadeladama.org, Cátedra Pedro Ibarra)

En el mes de Enero de 1931 Antonio

Vicente Caracena, practicante en medicina y cirugía, expone que, habiendo suplentes sin sueldo de practicantes titulares, se nombren practicantes suplentes sin sueldo del dispensario de la Cruz Roja; la petición es desestimada (Legajo 97/42).

\section{SERVICIOS PRESTADOS}

No disponiendo de series completas se han elaborado unas tablas representativas de la actividad sanitaria de la Casa de Socorro en la que se ubica la Cruz Roja ilicitana y la Ambulancia Sanitaria Urbana; esta primera tabla obedece a una semana concreta de junio de 1913 y los motivos de las curaciones son heridas varias (Tabla 1).

Los servicios que presta la Ambulancia Sanitaria Urbana y la Casa de Socorro durante los años 1927 (La Defensa y Elche, 20-01-1928), 1929 (Legajo 1463/2. Comisión de Beneficencia y Sanidad, 1929) y 1930 (Legajo 1463/2. Comisión de Beneficencia y Sanidad, 31-12-1930) son, según el Secretario de la Junta José Manuel Quiles los siguientes, careciendo de series completas como el año 1928 o anteriores a 1927 (Tabla 2).

Las curaciones de 1930 por meses son: Enero 59, Febrero 53, Marzo 52, Abril 52, Mayo 54, Junio 52, Julio 48, Agosto 65, Septiembre 48, Octubre 54, Noviembre 37y Diciembre 51 por lo que se observa cierta homogeneidad en los datos.

Las causas de los lesionados en los meses de Abril (Comunicación d 163, 08-05- 
1930), Mayo (Comunicación d 164/1, 31-051930) y Junio (Comunicación d 163, 05-071930) de 1930 y Enero (Comunicación d 164/2, 05-02-1931) y Abril (Comunicación d 164/2, 04-05-1931) de 1931 son los siguientes, adoleciendo del resto de meses de los años estudiados y de los años anteriores a 1930: las vacunaciones efectuadas en Mayo de 1930 se refieren a vacuna antivariólica procedente de la Inspección Provincial de Sanidad de Alicante (Comunicación d158, 09-04-1927; d163, 3105-1930) (Tabla 3).

\section{CONCLUSIONES}

La vida cotidiana de la Asamblea Local de Cruz Roja Española de Elche se inicia a finales del siglo XIX aunque de manera formal lo hará en 1909; tendrá una clara función social de asistencia sanitaria en la ciudad dando respuesta a las necesidades de mayor urgencia. Los servicios que presta hasta los años 30 del siglo XX son diversos, desde curación de heridas, traslado de enfermos, asistencia a entierros 0 vacunaciones. Su carácter independiente estará complementado con la ayuda municipal, a base de subvenciones tanto en efectivo como en personal, los socios y la organización de eventos para su sostenimiento (Comunicación d 163, 22-021930; La Voz de Levante, 15-01-1930 y 1901-1930).

Los principios en los que se basa la génesis de la Cruz Roja Internacional están presentes en la vida cotidiana de la $A L C R E$; la caridad quizá sea el cimiento de mayor calado escrito en la prensa ilicitana, desde las filas voluntarias de la caridad de los camilleros (El Tío Paco, 18-09-1909) al estilo "Landa” (Arenal, 1916) y resto de personal de la Casa de Socorro hasta las publicaciones de Milagros Gómez Soler (El Día, 29-05-1928); la universalidad es para todos los seres humanos (Elche, 24-121927) así como las recaudaciones de fondos para el Aguinaldo del soldado (Amanecer, 06-12-1925; Levante, 05-12-1925) o los temporales de Santa Pola (Amanecer, 08-051927; La Defensa, 29-05-1927 y 05-061927); la independencia económica y pública es defendida en varias ocasiones por su presidente, Sánchez Bernad, que afirma que el Dispensario es exclusivamente de dicha asociación e independiente de la Corporación Municipal y que el personal que presta sus servicios lo hace por altruismo y gratuitamente (Juventud, 31-051925 y 07-06-1925) aunque, con el tiempo, el consistorio contribuirá con personal propio; la imparcialidad, como esencia del movimiento, se dedica únicamente a socorrer a los individuos sin hacer distinción de raza, nacionalidad, religión, condición social o credo político (Cruz Roja Española, 2020) como la aportación para la guerra de los Balcanes (b 342/9, 26-10-1912).

\section{FUENTES Y BIBLIOGRAFIA}

Prensa histórica

Amanecer, PH-23, Año I, Núm. 6 de 6 de Diciembre de 1925.

Amanecer, PH-23, Año II, Núm. 36, Julio de 1926. 
Revista científica de la Asociación de Historia y Antropología de los Cuidados (Universidad de Alicante)

Amanecer, PH-23, Año III, Núm. 76 de 8 de Mayo de 1927.

Democracia, Año I, Núm. 6 de 26 de Septiembre de 1909.

Elche, PH-36, Año I, Núm. 23 de 18 de

Diciembre de 1927.

Elche, PH-36, Año I, Núm. 24 de 24 de

Diciembre de 1927.

Elche, PH-36, Año II, Núm. 28 de 29 de

Enero de 1928.

El Día, PH-172, Año XIV, Núm. 3.967 de

29 de Mayo de 1928.

El Ilicitano, PH-25, Año I, Núm. 26 de 2 de Diciembre de 1928.

El Papagayo, PH-350, Año II, Núm. 34 de 1 de Junio de 1924.

El Papagayo, PH-350, Año II, Núm. 35 de

8 de Junio de 1924.

El Tío Paco, Año I, Núm. 7 de 18 de

Septiembre de 1909.

Gaceta de Madrid, Núm. 181 de 29 de Junio de 1924.

Juventud, PH-42, Año I, Núm. 4 de 24 de Mayo de 1925.

Juventud, PH-42, Año I, Núm. 5 de 31 de Mayo de 1925.

Juventud, PH-42, Año I, Núm. 6 de 7 de Junio de 1925.

La Defensa, PH-66, Año XIV, Núm. 660 de 1 de Junio de 1924.

La Defensa, PH-66, Año XIV, Núm. 671 de 24 de Agosto de 1924.

La Defensa, PH-66, Año XVII, Núm. 809 de 29 de Mayo de 1927.

La Defensa, PH-66, Año XVII, Núm. 810 de 5 de Junio de 1927.

La Defensa, PH-66, Año XVIII, Núm. 841 de 29 de Enero de 1928.

La Defensa, PH-68, Año XVIII, Núm. 886 de 23 de Diciembre de 1928.

La Perla, Año I, Núm. 4 de 11 de

Septiembre de 1909.

La Voz de Levante, PH-107, Año I, Núm. 2 de 15 de Enero de 1930.

La Voz de Levante, PH-107, Año I, Núm. 3 de 19 de Enero de 1930.
Levante, PH-45, Núm. 5 de 5 de Diciembre de 1925.

Levante, PH-45, Núm. 6 de 20 de

Diciembre de 1925.

Nueva Illice, Año I, Núm. 1 de 7 de Junio de 1913.

Nueva Illice, PH-74, Año XI, Núm. 584 de 11 de Noviembre de 1923.

Nueva Illice, PH-74, Año XI, Núm. 589 de 16 de Diciembre de 1923.

Nueva Illice, PH-74, Año XII, Núm. 612 de 1 de Junio de 1924.

Nueva Illice, PH-74, Año XII, Núm. 613 de 8 de Junio de 1924.

Nueva Illice, PH-74, Año XII, Núm. 616 de 29 de Junio de 1924.

Nueva Illice, PH-74, Año XII, Núm. 618 de 13 de Julio de 1924.

Nueva Illice, PH-74, Año XII, Núm. 621 de 10 de Agosto de 1924.

Nueva Illice, PH-74, Año XII, Núm. 631 de 19 de Octubre de 1924.

Nueva Illice, PH-85, Año XIII, Núm. 662 de 31 de Mayo de 1925.

Nueva Illice, PH-85, Año XIII, Núm. 663 de 7 de Junio de 1925.

Nueva Illice, PH-85, Año XIII, Núm. 672 de 23 de Agosto de 1925.

Renovación, PH-17, Año I, Núm. 6 de 9 de Marzo de 1924.

Renovación, PH-17, Año I, Núm. 18 de 1 de Junio de 1924.

Renovación, PH-17, Año I, Núm. 19 de 8 de Junio de 1924.

Renovación, PH-17, Año I, Núm. 37 de 19 de Octubre de 1924.

Renovación, PH-17, Año II, Núm. 55 de 26 de Febrero de 1925.

Trabajo, Año IX, Núm. 333 de 2 de Enero de 1916.

Trabajo, PH-34, año XVII, Núm. 669 de 30 de Marzo de 1924.

\section{Documentos del Archivo Histórico Municipal de Elche (AHME)}


Acta 227, Sesión extraordinaria de 13 de

Enero de 1930, pp. 6-12 (AHME).

B 342/9, 26 de Octubre de 1912. Colección

Ephemera Pedro Ibarra (AHME).

Comunicación d 150, s/f. de Junio de 1924

(AHME).

Comunicación d 151, de 25 de Octubre de 1924 (AHME).

Comunicación d 155/1, de 17 de Octubre de 1925 (AHME).

Comunicación d158, de 9 de Abril de 1927

(AHME).

Comunicación d 159/2, de 30 de Marzo de 1928 (AHME).

Comunicación d 161, de 12 de Octubre de 1929 (AHME).

Comunicación d 163, de 22 de Febrero de 1930 (AHME).

Comunicación d 163, de 8 de Mayo de 1930 (AHME).

Comunicación d163, de 31 de Mayo de 1930

(AHME).

Comunicación d 164/1, de 31 de Mayo de 1930 (AHME).

Comunicación d 163, de 5 de Julio de 1930

(AHME).

Comunicación d 163, de 29 de Julio de 1930

(AHME).

Comunicación d 164/2, de 5 de Febrero de

1931 (AHME).

Comunicación d 164/2, de 4 de Mayo de

1931 (AHME).

Legajo 97/42 (AHME).

Legajo 1463/2. Comisión de Beneficencia y

Sanidad, 1929 (AHME)

Legajo 1463/2. Comisión de Beneficencia y Sanidad, 31 de Diciembre de 1930 (AHME). Legajo 1498/9 (AHME).

\section{BIBLIOGRAFÍA}

Arenal, C. (1916). La Cruz Roja sujeta a una prueba. La voz de la caridad, 92(26), 1 enero. Recuperado de

http://www.cervantesvirtual.com/obravisor/articulos-sobre-beneficencia-y- prisiones-volumen-ii--0/html/fefb5568-

82b1-11df-acc7-002185ce6064_6.html

Arrizabalaga, J. (2014). Introducción. En el $150^{\circ}$ aniversario de la Cruz Roja: nuevas cuestiones y enfoques en la historia del humanitarismo de guerra. Asclepio. Revista de Historia de la Medicina y de la Ciencia (Edición digital), 66(1), 1-27. Recuperado de https://doi.org/10.3989/asclepio.2014.01 Burke, P. (1996). Formas de hacer historia. Madrid: Alianza Editorial.

Clemente, J.C.; Polo, J.F. (2003). La prensa humanitaria en la España Contemporánea (1870-1989). Madrid: Ed. Fundamentos.

Cruz Roja Española. Recuperado de http://www.cruzroja.es

Cruz Roja Española en Elche. Recuperado de http://cruzrojaelche.org

Gómez Martínez, M.R. (2018). Crónica de la pobreza. Orígenes de la Asistencia Social en una ciudad del mediterráneo. Elche, 1923-1930. Elche: Cátedra Pedro Ibarra. Universidad Miguel Hernández.

González García, A. (2013). Los manuales de formación de la Cruz Roja durante la epidemia de gripe de 1918-1919. Cultura de los cuidados, 17(36): 19-28. Recuperado de http://dx.doi.org/10.7184/cuid.2013.36.03

Hernández-Conesa, J.M. (2014). 150 años de la Cruz Roja Española. La acción humanitaria como derecho humano. Índex de Enfermería, 23(4), oct-dic. Recuperado de $\quad$ http://dx.doi.org/10.4321/S113212962014000300014

Lujano Arenas, A.; Ruiz-Berdún, D. (2019). Los comienzos de una institución centenaria: Hospital Central de la Cruz Roja San José y Santa Adela. Temperamentvm. Revista Internacional de Historia y Pensamiento enfermero, 15. Recuperado de https://orcid.org/0000-0001-8884-6139

Martínez Sabater, A., Juárez Colom, J., Solano Ruiz, M.C., Siles González, J. (2017). Las nodrizas en el periódico ABC (1903-1920). Cultura de los cuidados, 21(48).

Recuperado de

http://dx.doi.org/10.14198/cuid.2017.48.11 
Revista científica de la Asociación de Historia y Antropología de los Cuidados (Universidad de Alicante)

Más Espejo, M. (2016). El cuerpo de damas enfermeras de la Cruz Roja Española: formación y contribución a la labor cuidadora y social. (Tesis de doctorado no publicada). Departamento de Enfermería, Universidad de Alicante: Alicante. Recuperada de http://hdl.handle.net/10045/62388

Monge Juárez, M. (2015). Agua, tierra y capital. La construcción de una ciudad contemporánea. Elche, 1884-1903. Elche: Cátedra Pedro Ibarra. Universidad Miguel Hernández.

Ors Montenegro, M. (1984). La prensa ilicitana, 1836-1980. Alicante: Caja de Ahorros Provincial.
Ors Montenegro, M. (2010). Cátedra Pedro Ibarra. Recuperado de http://www.elche.me Rueda Cuenca, J., Martinez Marco, E., Ors Montenegro, M., Salazar Agulló, M.(2018). La epidemia de gripe española en el Baix Vinalopó (1918-1919). Elche: Cátedra Pedro Ibarra, Universidad Miguel Hernández.

Siles González, J. (1996). Enfermería y conflictos bélicos. Una historia por hacer. Índex de Enfermería, (15), 7-8. Recuperado de http://www.index-f.com/indexenfermeria/15/0708.php

Tabla 1. Curaciones verificadas en la Casa de Socorro última semana (Nueva Illice, 07-061913)

\begin{tabular}{|l|l|}
\hline Diego Pérez Sánchez & $\begin{array}{l}\text { Herida contusa en la región superciliar derecha y otra en la mesetérica } \\
\text { derecha y diferentes erosiones en la cara }\end{array}$ \\
\hline Juan Ruiz Agulló & Herida contusa en el interior del cuero cabelludo \\
\hline Francisco Aracil Gómez & Herida contusa en el labio inferior \\
\hline Teresa Agulló Sánchez & $\begin{array}{l}\text { Herida contusa en la región parietal derecha, de } 4 \text { cm de longitud de } \\
\text { pronóstico leve }\end{array}$ \\
\hline José Quiles Jaén & Herida punzante en la mano derecha \\
\hline Carmen Montero San & Herida incisa en la rodilla derecha y erosiones en los brazos \\
\hline Antonia Agulló Sánchez & Herida contusa en la cara superior del carpo de la mano derecha \\
\hline
\end{tabular}




\begin{tabular}{|l|c|c|c|}
\hline Tabla 2. Servicios prestados & $\mathbf{1 9 2 7}$ & $\mathbf{1 9 2 9}$ & $\mathbf{1 9 3 0}$ \\
\hline $\begin{array}{l}\text { Traslado de heridos en camilla al Hospital o } \\
\text { a su domicilio }\end{array}$ & 8 & 6 & 7 \\
\hline Traslado de enfermos en camilla al Hospital & 2 & 2 & \\
\hline $\begin{array}{l}\text { Traslado de cadáveres en camilla al Depósito } \\
\text { Judicial o a su domicilio }\end{array}$ & 5 & 5 & 5 \\
\hline Asistencia a incendios & 1 & 2 & \\
\hline Personas asistidas en la vía pública & 5 & 5 & \\
\hline $\begin{array}{l}\text { Personas acompañadas a su domicilio después } \\
\text { de curadas u otros lugares de la población }\end{array}$ & 18 & 15 & \\
\hline Personas socorridas con/en metálico & 2 & 11 & \\
\hline Personas socorridas con tapabocas para niños & 200 & & \\
\hline Personas socorridas con medicamentos & 8 & 12 & \\
\hline Primeras curas efectuadas en la Casa de Socorro & $\mathbf{3 3 0}$ & $\mathbf{3 7 0}$ & $\mathbf{6 2 5}$ \\
\hline Retenes & 6 & 8 & 10 \\
\hline Puestos de socorro fuera del domicilio social & 2 & & \\
\hline Salidas a instrucción, ejercicios o maniobras & 1 & 3 & \\
\hline Asistencias a corridas de Toros & & 3 & \\
\hline Asistencias a entierros en corporación & & 3 & \\
\hline & & & \\
\hline Total & $\mathbf{5 8 8}$ & $\mathbf{4 4 5}$ & $\mathbf{6 4 7}$ \\
\hline
\end{tabular}

\begin{tabular}{|l|c|c|c|c|c|}
\hline $\begin{array}{l}\text { Tabla 3. } \\
\text { Causas lesiones }\end{array}$ & Abril 1930 & Mayo 1930 & Junio 1930 & Enero 1931 & Abril 1931 \\
\hline Acc. trabajo & 21 & 4 & 16 & 16 & 5 \\
\hline Mordedura & & 1 (perro) & 1 (perro) & & 1 (caballo) \\
\hline Riña & 1 & 2 & 3 & 1 & \\
\hline Atropello & & 1 & 5 & $\begin{array}{c}1 \text { (auto) } \\
\text { (bicicleta) }\end{array}$ & 3 (auto) \\
\hline Hecho casual & 34 & 45 & 32 & 26 & 35 \\
\hline Vacunaciones & & $\mathbf{1 9 4}$ & 55 & & 1 \\
\hline Intoxicaciones & & & & & $\mathbf{4 5}$ \\
\hline & & & $\mathbf{1 1 2}$ & $\mathbf{4 5}$ & \\
\hline Total & $\mathbf{5 6}$ & $\mathbf{2 4 7}$ & & & \\
\hline
\end{tabular}

